\title{
A Quasi-Experiment on the Effectiveness of Cardiac Rehabilitation in Quality of Life of Cardiac Patients with the Caregivers' Involvement
}

\author{
Ruthpackiavathy Rajen Durai ${ }^{1}$, Khairuddin Idris ${ }^{2}$, Oteh Maskon ${ }^{3}$, Muhammad Hibatullah Romli ${ }^{4}$, \\ Najibah Abdul Razak ${ }^{5}$ \\ ${ }^{\text {I} S e n i o r ~ L e c t u r e r, ~ D e p a r t m e n t ~ o f ~ N u r s i n g, ~ F a c u l t y ~ o f ~ M e d i c i n e ~ a n d ~ H e a l t h ~ S c i e n c e s, ~ U n i v e r s i t y ~ P u t r a ~ M a l a y s i a, ~}$ \\ Serdang, Selangor, Malaysia \\ ${ }^{2}$ Associate Professor, Institute of Social Sciences, University Putra Malaysia, Serdang, Selangor, Malaysia \\ ${ }^{3}$ Professor, An-Nur Specialist Hospital, Selangor, Malaysia \\ ${ }^{4}$ Senior Lecturer, Department of Rehabilitation Medicine, Faculty of Medicine and Health Sciences, University \\ Putra Malaysia, Serdang, Selangor, Malaysia \\ ${ }^{5}$ PhD Student, University Technology MARA, Selangor, Malaysia
}

*Correspondence

Ruthpackiavathy Rajen Durai

Senior Lecturer, Department of Nursing, Faculty of Medicine and Health Sciences, University Putra Malaysia, Serdang, Selangor, Malaysia.

Email: ruthpackiavaty@upm.edu.my

\begin{abstract}
Introduction: Coronary Heart Disease can result in impaired quality of life which can inhibit an early recovery with successful outcomes for cardiac patients. Objective: To investigate the effect of a structured cardiac education and early intervention cardiac rehabilitation program on quality of life in cardiac patients involving caregivers. Method: A quasi experimental study with a purposive sampling was carried out where 132 acute coronary syndrome patients hospitalized for treatment were recruited and allocated to the experiment and control group with and without caregivers. A structured educational intervention and cardiac rehabilitation was initiated for the experimental group with and without caregivers. The outcome was measured using the World Health Organization Quality Of LifeBREF (WHOQOL-BREF) instrument.Results: Data was measured with repeated measures ANOVA between baseline, discharge and follow-up between the intervention and control group with $p<0.05$ There was a statistically significant difference in QOL in both the groups with and without caregivers in the following domains: psychological health $(F=3.784, p=0.002)$; social relationship $(F=4.267, p=0.000)$ and environment $(F=3.578$, $p=0.004)$. There was not a statistically significant difference between both the groups in the physical health domain $(F=1.316, p=0.266)$. Conclusion: The results indicated that a structured cardiac educational intervention and cardiac rehabilitation with the involvement of the caregivers have significant effects on the quality of life of cardiac patients. The findings provide useful evidence to improve health outcomes of acute coronary syndrome patients involving the caregivers.
\end{abstract}

Key words: Cardiac patients, cardiac rehabilitation, quality of life, caregivers.

This is an Open Access article that uses a fund-ing model which does not charge readers or their institutions for access and distributed under the terms of the Creative Commons Attribution License (http://creativecommons.org/licenses/by/4.0) and the Budapest Open Access Initiative (http://www.budapestopenaccessinitiative.org/read), which permit unrestricted use, distribution, and reproduction in any medium, provided the original work is properly credited.

\section{Introduction}

Cardiovascular disease is the top non-communicable disease worldwide, the leading cause for mortality, and a major contributor to the reduction of quality of life [1]. Furthermore, cardiovascular diseases also impacted the economy and social burden while reducing productivity and increasing disability of the affected individuals, the environment and the country $[1,2]$. Problems related to cardiovascular disease are worse in developing and under-developed countries [1, 2]. For example, in Malaysia, cardiovascular disease is the leading health problem which contributes to $24.7 \%$ of total deaths and a major culprit for morbidity. Among the cardiovascular diseases, Acute Coronary Syndrome (ACS) is a lifethreatening disease which describes clinical conditions ranging from unstable angina (UA) to non-ST-segment

Rajen Durai et al ASIAN PACIFIC JOURNAL OF NURSING AND HEALTH SCIENCES, 2021; 4(1):1-10 
elevation myocardial infarction (NSTEMI) to STsegment elevation myocardial infarction (STEMI) [3]. The sudden attack and reduced blood flow to the heart tissue, even if no cell death may alter the cardiac function; this may cause other health and functional issues in the future [3]. With the current advancement of medical knowledge and technology, the number of people surviving and living with cardiovascular diseases is increasing [3, 4-8]. These had made cardiac rehabilitation as warranted in alleviating the functions and quality of life of the cardiac patients.

Cardiac rehabilitation (CR) is a multi-component intervention generally comprising of structured exercise training, psychological support and education to promote positive lifestyle changes [6]. The goal of $\mathrm{CR}$ is to promote recovery, maximize the quality of life (QOL) and to overcome the barriers in attending CR [9, 10]. It comprises of risk reduction strategies such as nutritional counseling, management of lipid levels, weight, diabetes, hypertension, smoking cessation, psychological intervention and physical activity, counseling, exercise training and patient education [11, 12]. CR has been found to be effective in reducing the risk of mortality, reducing hospital admission, improving functions and QOL of the patients [5-6, 13-14]. It is a safe and effective way to treat patients who have experienced cardiac events [15-16]. Although the many benefits of CR has been evidenced through research $[5,17]$, it is still underutilized [18].

CR consists of four phases; (1) clinical, (2) home, (3) outpatient rehabilitation, and (4) post-cardiac rehabilitation for maintenance - however, phase (1) and (2) are considered as the most crucial as this is where the patient is most vulnerable and being introduced to the program [19]. Phase $1 \mathrm{CR}$, which begins during hospitalization soon after a cardiac event, consists of education and the initiating step to start activity to promote patient understanding of the importance of CR in their recovery process, secondary prevention strategies and compliance. It consists of low-level, supervised activity (i.e., standing up, walking) and initial basic education for the patient and family which includes describing the signs and symptoms, medication regimen, rest and activity, and how to improve the modifiable coronary heart disease (CHD) risk factors [20]. Phase 2 is the interval continuation and advancement of the program of phase 1 before advancing into a more distinctive rehabilitation program in phase 3 . The Phase 1 rehabilitation program may begin as soon as 3-4 days while in hospital [21].
Although the cardiac rehabilitation program (CRP) was found to be effective, there are several issues identified. Certain cardiac rehabilitation programs (CRPs) are not comprehensive-focused but on unifactorial intervention such as education-only or exercise only intervention [5, 14]. Guidelines on CR are also criticized [8]. Multifactorial CR has greater effectiveness and should be considered when planning for such module. However, CR was found to be costly, requires high manpower and resources [19]. This has become a burden for low and limited resources countries to conduct a comprehensive CRP. For example in Malaysia, clinical facilities are overcrowded, inadequate number of healthcare staff, overburdened staff and high financial burden on healthcare expenditure due to subsidized health has made high-intensive, high-resources CR as a challenge [22]. In addition, CRP usually focused on the individual patients and the healthcare providers. Most CRP utilized clinical setting and facilities while home-based program is potential, however under explored [23]. Furthermore, many CRPs do not include the caregivers as one important party although they can play an important role. With the shortened hospital stays and earlier discharge of patients, there has been an increased need for family caregivers in the home and these informal caregivers are among the nation's most valuable resources. [24, 25]. Family members who are caregivers also perceived cardiac event as a serious condition and are impacted by it. The active involvement of caregivers in CR present an opportunity to employ factors of family dynamics, motivation, monitoring and support as they come together to influence the cardiac patient's participation in and compliance with cardiac education and rehabilitation [26]. This view was also supported by some of the health professionals who stated that active cooperation of family members was an essential component in such services especially when the patient cannot be directly educated due to their health condition.[27, 28].

Studies included in the review by Shepherd \& While (2012) utilized health-related QOL instruments [13]. QOL is understood as a broader ranging concept which affected in a complex way the person's physical health, psychological state, level of independence, social relationships, personal beliefs and their relationship to salient features of their environment [29]. As cardiovascular disease has wider impact than only on health, therefore it is beneficial to investigate if intervention may also affect other domains of QOL. In Malaysia, a clinical practice guideline on cardiovascular management including CR gives attention on smoking cessation, diet, encourage physical activities and regular exercise, and comorbidity management [30]. However, there are not many negligible experimental studies

\section{Rajen Durai et al TSIAN PACIFIC JOURNAL OF NURSING AND HEALTH SCIENCES, 2021; 4(1):12-21}


available on $\mathrm{CR}$ in Malaysia. Only a longitudinal observation study and case report were found [31, 32]. Thus, it is a gap to develop and investigate the effectiveness of a CRP that is relevant to local context, cost-effective, is able to be performed at home, involve the caregivers and examine its outcome on the general aspect of QOL. The aim of this research is to examine the effect of a structured early intervention CRP among CHD patients with ACS admitted to the hospital for treatment with the involvement of caregivers.

\section{Methodology}

\section{Study Design}

This was a quasi-experimental design with control $(n=70)$ and experimental $(n=70)$ groups to examine the effectiveness of an early CRP in QOL among ACS patients with and without caregivers. The experimental group received a structured early CRP and routine care and control group received only routine care. The study was conducted with the approval of the Ethics Committee (FPSK(EXP15)P075 / FF-2015-249) in one tertiary teaching hospital situated in Kuala Lumpur, Malaysia.

\section{Participants and Data Collection Procedure}

The study was conducted between June 2015 and December 2015. Potential participants were recruited from the Coronary Care Unit (CCU), Coronary Rehabilitation Ward (CRW) and two medical wards which admitted cardiac patients for treatment. The purposive sampling method was chosen to ensure equal and balanced characteristic representation of the participants. The inclusion criteria were: (1) patients diagnosed with CHD and hospitalized for Acute Coronary Syndrome, (2) patients between the age of 25 and 75 years old, (3) those who understood either the Malay language or the English language. The exclusion criteria were: (1) not getting clearance by the medical physician or consultant due to very ill or high risk to participate in rehabilitation, (2) patients who refused to participate and (3) surgical patients. An informed consent was obtained prior to conducting the study and the potential participants were explained about the study. Data were collected in three phases: the first phase was before commencing cardiac care and intervention (averagely between 3-4 days); the second phase was on discharge from the hospital (averagely on the $8^{\text {th }}$ day); and the third phase was when these participants came for follow up to the clinic (averagely on the $10^{\text {th }}$ week). Data was collected from the control group first to prevent contamination until the targeted sample was reached [33] and was completed during the first three months of the study. Data collection from the experimental group commenced after completion of the control group and when the cardiologist in charge had referred the participant for early CR intervention.

The cardiologists in charge, nurses, dieticians, pharmacists and physiotherapists provided the routine care which was more generic in nature and consisted of professional-centered services on self-management at home, instructions on medication and information leaflets about cardiac risk factors, healthy diet and smoking cessation. It was made sure that the caregiver, if available, accompanied the participant during cardiac care each time. For the participants in the experimental group, client-empowerment approach with more specific, individualized instruction and education was provided with the use of a comprehensive $\mathrm{CR}$ manual regarding the heart and its conditions, diet, exercise and activity, risk factors modification, treatment and management, and the importance of CR. Since early CR intervention is the initiating process, the researcher had made all efforts possible to make the participants and caregivers understand the educational intervention with simple and clear instructions and explanations referring to the manual. All questions by either the participants or caregiver were answered. The researcher together with the caregiver started the initial phase with the participants sitting up in bed followed by standing at the bedside with assistance and continued with progressive activities of daily living sessions and walking exercises, and reinforcements based on the patient's condition during the patient's length of stay in the hospital. The participants were advised to do self-care activities while the caregiver was monitoring with the researcher observing the activities. It was made sure that the caregiver was involved throughout the CR session with the respective participants and the daily activities performed were recorded in a log-book. The recording in the log-book will be continued at home and will be collected upon follow-up in the cardiology clinic. As for the group without caregiver the participants did their self-care activities on their own but called the nurses for assistance when needed. Cardiac self-management and adopting a healthy lifestyle was emphasized throughout the program and before discharge, and clear explanations were given to both parties regarding the activities the participants had to follow according to the CR manual.

Data on demographic information was collected during baseline while on QOL the WHOQOL-BREF instrument was used on each time point that is baseline, on discharge and during follow-up in the clinic. The reliability and validity of the WHOQOL-BREF was Cronbach's alpha 0.66 to 0.84 and this instrument has 
been used with coronary diseases. [34, 35]. WHOQOLBREF is a 26 item self-report instrument addressing four 4 domains of QOL: physical health, psychological health, social relationships and environment. Each item is scored by a five-point likert scale where higher rating indicates positive outcome except on three items (item 3 , 4 ,and 26) which have reverse rating (i.e. higher rating indicates negative outcome). Total score was calculated by adding the rating of each item according to the domains and corrected with the rating score for the reverse item. The raw score was then converted into a transformed score of 100 where higher score indicates better QOL. [34-36]. Prior to the third phase of data collection, a discussion session was held with these participants and caregivers in a room in the clinic and the log-book was collected. This was to have a better understanding about the participants' and caregivers' compliance to all that had been taught with regards to their cardiac condition and CR.

\section{Statistical Analysis}

The SPSS version 22 was used to analyze the data. Chi Square and percentages were used to measure the descriptive data. Repeated-measures Analysis of variance (ANOVA) were carried out whereby the mean differences between baselines, discharge and follow-up measurements were analyzed for QOL for both the experimental and control groups.

\section{Results}

The flow of the research is illustrated in figure 1.

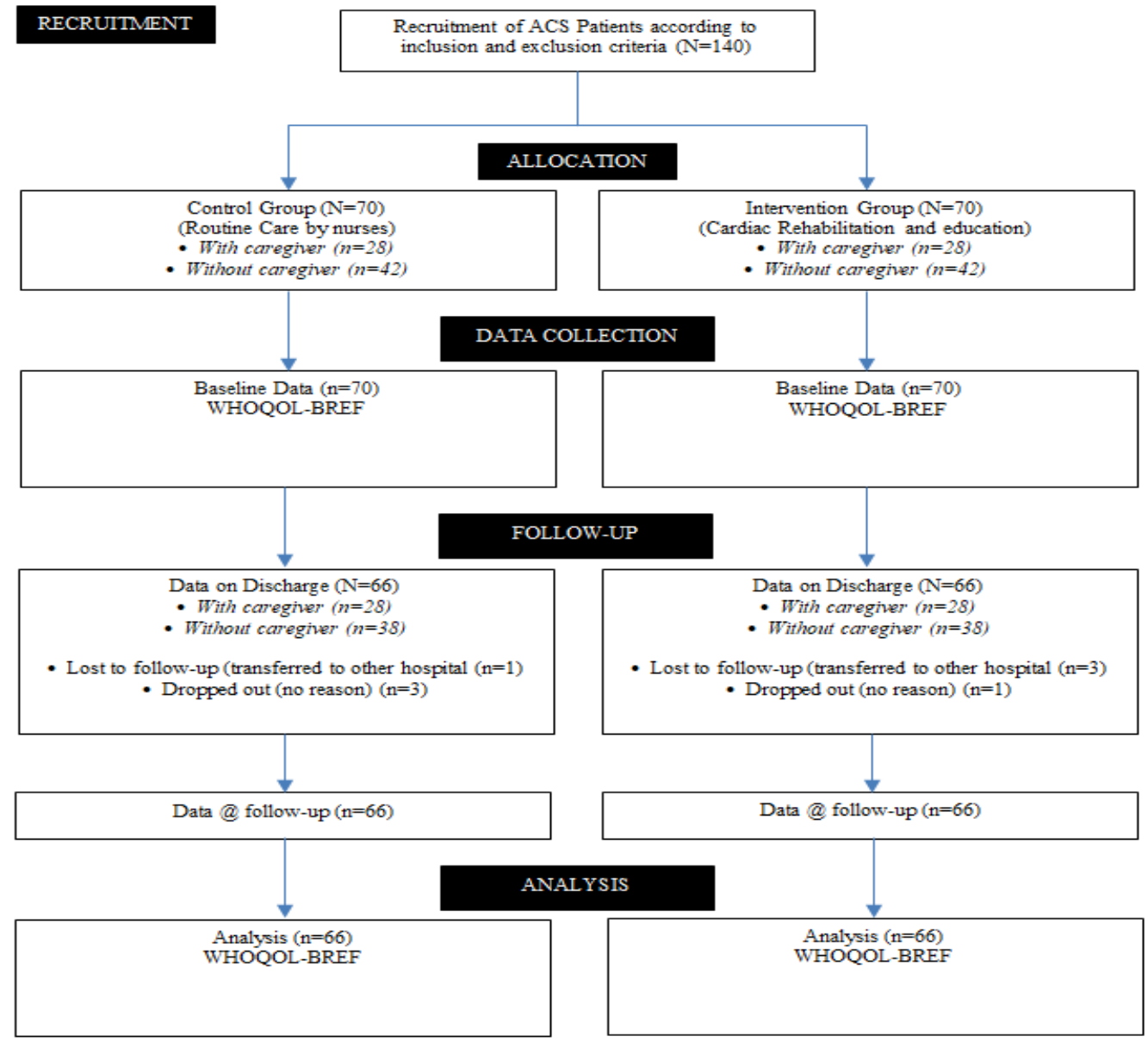

Fig. 1: Flow of the study

There was no significant difference found on the demographic characteristics on the participants between both groups. Both groups were balanced in terms of caregiver attendance. Majority of the participants were

Rajen Durai et al ASIAN PACIFIC JOURNAL OF NURSING AND HEALTH SCIENCES, 2021; 4(1):12-21 
male $(68.2 \%)$ for both the groups. The different ethnic participants were nearly the same in both groups. Majority of the participants were married (intervention $=93.9 \%$; control $=89.4 \%$ ) and had obtained secondary level education $(63.6 \%)$ in both groups. However, majority of the participants in the control group were not employed $(62.1 \%)$ compared to the intervention group $(51.5 \%)$ where majority were employed. Around one-third of the participants in the control and experimental group had history of CHD but higher for family history with such diseases. Majority of the participants (intervention $=89.4 \%$; control $=80.3 \%$ ) had other illnesses. Less than half of the participants smoked in both groups. Detailed description of the demographic information of the participants can be found in Table 1.

Table 1: Socio demographic variables of participants

\begin{tabular}{|c|c|c|c|c|c|}
\hline & & Gr & & & \\
\hline & & Intervention $(\mathrm{n}=66)$ & Control $(n=66)$ & $\chi^{2}$ & $\mathrm{P}$ \\
\hline Caregiver & Caregiver & $28(42.4 \%)$ & $28(42.4 \%)$ & 0.000 & 1.000 \\
\hline & No Caregiver & $38(57.6 \%)$ & $38(57.6 \%)$ & & \\
\hline Diagnosis & UA & $25(37.9 \%)$ & $25(37.9 \%)$ & 0.000 & 1.000 \\
\hline & STEMI & $16(24.2 \%)$ & $16(24.2 \%)$ & & \\
\hline & NSTEMI & $25(37.9 \%)$ & $25(37.9 \%)$ & & \\
\hline Gender & Male & $45(68.2 \%)$ & $45(68.2 \%)$ & 0.000 & 1.000 \\
\hline & Female & $21(31.8 \%)$ & $21(31.8 \%)$ & & \\
\hline Age & $<39$ & $6(9.1 \%)$ & $1(1.5 \%)$ & 4.670 & 0.097 \\
\hline & $40-59$ & $24(36.4 \%)$ & $22(33.3 \%)$ & & \\
\hline & $>60$ & $36(54.5 \%)$ & $43(65.2 \%)$ & & \\
\hline Ethnicity & Malay & $32(48.5 \%)$ & $30(45.5 \%)$ & 0.133 & 0.936 \\
\hline & Chinese & $24(36.4 \%)$ & $25(37.9 \%)$ & & \\
\hline & Indian & $10(15.2 \%)$ & $11(16.7 \%)$ & & \\
\hline Marital Status & Married & $62(93.9 \%)$ & $59(89.4 \%)$ & 5.763 & 0.124 \\
\hline & Not Married & $4(6.1 \%)$ & $3(4.5 \%)$ & & \\
\hline & Separated & $0(0.0 \%)$ & $2(3.0 \%)$ & & \\
\hline & Widowed & $0(0.0 \%)$ & $2(3.0 \%)$ & & \\
\hline Education Level & Primary & $14(21.2 \%)$ & $18(27.3 \%)$ & 1.531 & 0.675 \\
\hline & Secondary & $42(63.6 \%)$ & $42(63.6 \%)$ & & \\
\hline & Diploma & $7(10.6 \%)$ & $4(6.1 \%)$ & & \\
\hline & Graduate & $3(4.5 \%)$ & $2(3.0 \%)$ & & \\
\hline Employment Status & Employed & $34(51.5 \%)$ & $25(37.9 \%)$ & 2.482 & 0.115 \\
\hline & Not Employed & $32(48.5 \%)$ & $41(62.1 \%)$ & & \\
\hline History of CHD & Yes & $24(36.4 \%)$ & $22(33.3 \%)$ & 0.133 & 0.715 \\
\hline & No & $42(36.4 \%)$ & $44(66.7 \%)$ & & \\
\hline Family History & Yes & $34(51.5 \%)$ & $32(48.5 \%)$ & 0.121 & 0.728 \\
\hline & No & $32(48.5 \%)$ & $34(51.5 \%)$ & & \\
\hline Smoking & Yes & $30(45.5 \%)$ & $30(45.5 \%)$ & 0.000 & 1.000 \\
\hline & No & $36(54.5 \%)$ & $36(54.5 \%)$ & & \\
\hline Other Illness History & Yes & $59(89.4 \%)$ & $53(80.3 \%)$ & 2.121 & 0.145 \\
\hline & No & $7(10.6 \%)$ & $13(19.7 \%)$ & & \\
\hline
\end{tabular}

Table 2 reveals the results by multifactorial repeatedmeasures ANOVA according to the domains in WHOQOL-BREF between the experimental and control group with and without caregiver. There was a statistically significant difference in the psychological health $(F=3.784, p=0.002)$, social relationship $(F=4.267$, $p=0.000)$ and environment $(F=3.578, p=0.004)$ domains between the experimental group with and without caregiver and control group with and without caregiver over the three times. However, there was no statistically significant difference in the physical health domain $(F=1.316, \quad p=0.266)$ between the experimental group

\section{Rajen Durai et al ASIAN PACIFIC JOURNAL OF NURSING AND HEALTH SCIENCES, 2021; 4(1):12-21}


with and without caregiver and control group with and discharge and follow-up.

without caregiver over the three times that is baseline,

Table 2: Within-between group analysis on WHOQOL-Bref outcome using multi-factor repeated-measures ANOVA

\begin{tabular}{|c|c|c|c|c|c|c|c|c|c|c|}
\hline \multirow[t]{2}{*}{$\begin{array}{l}\text { WHOQOL- } \\
\text { Bref Domain }\end{array}$} & \multicolumn{2}{|c|}{ Group / Time } & \multicolumn{2}{|c|}{ Baseline } & \multicolumn{2}{|c|}{ Discharge } & \multicolumn{2}{|c|}{ Follow-up } & \multicolumn{2}{|c|}{$\begin{array}{c}\text { Multi-factor } \\
\text { repeated-measures } \\
\text { ANOVA }\end{array}$} \\
\hline & & & Mean & SD & Mean & SD & Mean & SD & $F$ & Sig. \\
\hline \multirow[t]{6}{*}{ Physical } & Intervention & Overall $(\mathrm{n}=66)$ & 44.70 & 17.21 & 47.39 & 10.67 & 63.36 & 9.29 & 1.316 & 0.266 \\
\hline & & Caregiver $(\mathrm{n}=28)$ & 44.64 & 20.177 & 43.250 & 8.951 & 64.464 & 9.856 & & \\
\hline & & No Caregiver $(\mathrm{n}=38)$ & 44.74 & 14.950 & 50.447 & 10.912 & 62.553 & 8.901 & & \\
\hline & Control & Overall $(n=66)$ & 42.23 & 21.66 & 45.11 & 8.68 & 59.35 & 10.14 & & \\
\hline & & Caregiver $(n=28)$ & 45.43 & 24.835 & 45.679 & 7.503 & 59.000 & 9.568 & & \\
\hline & & No Caregiver $(\mathrm{n}=38)$ & 39.87 & 18.992 & 44.684 & 9.533 & 59.605 & 10.658 & & \\
\hline \multirow[t]{6}{*}{ Psychological } & Intervention & Overall $(n=66)$ & 56.71 & 16.48 & 56.74 & 12.25 & 70.85 & 12.10 & 3.784 & $0.002 *$ \\
\hline & & Caregiver $(\mathrm{n}=28)$ & 55.286 & 19.121 & 51.714 & 11.941 & 71.107 & 12.294 & & \\
\hline & & No Caregiver $(\mathrm{n}=38)$ & 57.763 & 14.404 & 60.447 & 1.234 & 70.658 & 12.124 & & \\
\hline & Control & Overall $(n=66)$ & 59.21 & 14.54 & 58.45 & 9.85 & 66.36 & 10.33 & & \\
\hline & & Caregiver $(\mathrm{n}=28)$ & 61.929 & 16.303 & 58.143 & 8.877 & 65.500 & 9.935 & & \\
\hline & & No Caregiver $(\mathrm{n}=38)$ & 57.211 & 12.949 & 58.684 & 10.619 & 67.000 & 10.702 & & \\
\hline \multirow{6}{*}{$\begin{array}{l}\text { Social } \\
\text { Relationship }\end{array}$} & Intervention & Overall $(n=66)$ & 57.50 & 12.67 & 61.80 & 10.43 & 69.91 & 10.67 & 4.267 & $0.000 *$ \\
\hline & & Caregiver $(\mathrm{n}=28)$ & 59.393 & 13.814 & 62.321 & 10.729 & 72.964 & 10.039 & & \\
\hline & & No Caregiver $(\mathrm{n}=38)$ & 56.105 & 11.754 & 61.421 & 10.324 & 67.658 & 10.688 & & \\
\hline & Control & Overall $(n=66)$ & 59.86 & 12.48 & 57.48 & 12.40 & 64.44 & 12.12 & & \\
\hline & & Caregiver $(\mathrm{n}=28)$ & 62.321 & 13.236 & 58.071 & 10.708 & 63.250 & 11.034 & & \\
\hline & & No Caregiver $(\mathrm{n}=38)$ & 58.053 & 11.743 & 57.053 & 13.632 & 65.316 & 12.930 & & \\
\hline \multirow[t]{6}{*}{ Environment } & Intervention & Overall $(n=66)$ & 54.64 & 12.01 & 57.83 & 8.2 & 67.41 & 8.41 & 3.578 & $0.004 *$ \\
\hline & & Caregiver $(n=28)$ & 53.536 & 13.209 & 55.036 & 9.228 & 67.536 & 9.739 & & \\
\hline & & No Caregiver $(\mathrm{n}=38)$ & 55.447 & 11.159 & 59.895 & 6.758 & 67.316 & 7.411 & & \\
\hline & Control & Overall $(\mathrm{n}=66)$ & 55.09 & 10.83 & 55.58 & 7.62 & 62.61 & 8.49 & & \\
\hline & & Caregiver $(\mathrm{n}=28)$ & 57.321 & 11.892 & 55.643 & 6.778 & 62.071 & 6.949 & & \\
\hline & & No Caregiver $(\mathrm{n}=38)$ & 53.447 & 9.819 & 55.526 & 8.278 & 63.000 & 9.546 & & \\
\hline
\end{tabular}

Although there was a steady increase in mean in all the withdrawal and high adherence on the program as groups, the experimental group had a higher increase compared to the control group and the experimental group with caregiver scored the highest compared to all the groups. This suggested that the experimental group with caregiver experienced better QOL followed by the experimental group without caregiver than the control group. This means that there is a difference in the QOL between the experimental group and the control group and can be concluded that the structured educational early intervention and cardiac rehabilitation with the caregiver was effective.

\section{Discussion}

This study may be generalized to the Malaysian context as it represents the proportion of the population on three main ethnicities. Malaysia is a multiracial country with three major ethnic groups; the Malays $(68.6 \%)$, followed by the Chinese (23.4\%) and the Indians (7.0\%) [37]. The different ethnic participants were nearly the same in both groups and ACS remains a disease that affects all the three races in Malaysia [38]. The low number of evidenced by the log-book indicates that this CRP as feasible. Majority of the participants had obtained secondary level education which made it possible for the CRP to take place in a complacent and reliable manner. More male participants were available in this study which denotes that male participants are at a higher risk of cardiovascular diseases compared to the female participants [39, 40]. It is also noted that the male to female ratio in this study is $2: 1$ which is similar to Zuhaid et al. [41] but not congruent with other studies which recorded the ratio as 3:1 [42]. This is acceptable as the results differ between countries. Older participants were available in this study and this is in concordance with the cardiac population in the country [37] which is more common among older age group people [43, 44].

Overall, early cardiac rehabilitation program helps to improve the QOL of the cardiac patients. This is in concordance with other studies investigating cardiac rehabilitation effect on QOL in the review by Shepherd \& While [13]. Experiencing a cardiac event can be difficult times and support during this time is very

\section{Rajen Durai et al ASIAN PACIFIC JOURNAL OF NURSING AND HEALTH SCIENCES, 2021; 4(1):12-21}


important, especially emotional support as it provides the feeling of being loved and cared for [24, 45, 46] and it helps with physical activity, nutritional and smoking cessation programs [4]. With the involvement of the caregiver, healthy lifestyle behaviors after CR may be maintained [47-49]. Lack of family support is associated with a significantly lower level of health related QOL [50]. It can be confirmed that early CR intervention improves QOL and functional status of coronary artery disease patients $[51,52]$. On the other hand, a study conducted on female participants in an experimental and control group did not find any significant differences in the improvement in QOL between the experimental and control group [53].

The findings of this study may be influenced by the structured educational early intervention with the involvement of the caregivers, and understanding of the participants regarding CR and its objectives. Only a few studies have looked at the component of CR $[54,55,56]$ while some studies revealed that educational interventions increased knowledge and behavior changes [42, 55, 57], and that it is imperative to provide informational, psychological and social support in enabling patients to recover from ACS [31, 45]. When patients understood the benefits, together with the caregivers, they appreciated the fact that they were involved in the structured educational early intervention and initiation of cardiac rehabilitation. CR has shown to decrease risk factors of coronary artery disease in reducing the mortality rate to about $20-31 \%$ [27, 32]. Most importantly, the results revealed that the impact of an educational early intervention and CR on QOL was positive in that it was capable of demonstrating its effectiveness in enhancing the QOL of ACS patients. When the participants have a better understanding of their condition and the benefits of cardiac rehabilitation, they tend to comply, continue to the next phases of CR and practice healthy lifestyle behaviors. Seeing the result, it may also motivate the caregivers to practice healthy lifestyle behaviors and in doing so the morbidity and mortality rate will reduce leading to a healthy community. The limitation is this study is the study was conducted in one facility in an urban area, therefore generalizability of the study to the whole population in the country is at stake. The use of WHOQOL-BREF has been criticized as less suitable to be used among the cardiac population [58]. However, the WHOQOL-BREF is a self-administered questionnaire thus minimized the involvement of the researcher in tampering the data.

\section{Conclusion}

Early intervention of CR during hospitalization provides awareness to the patients and caregivers towards the benefits of CR to achieve optimum health and QOL. The involvement of the caregiver may help to reduce the financial burden and economic impact on the patient, family, hospital and country. The findings of this study add essence to evidence-based practice for nurses. The goal of CR is to develop a patient's optimum physical, emotional, psychological and social potential.

\section{Abbreviations}

CR: Cardiac Rehabilitation; CRP: Cardiac Rehabilitation Program; CRPs: Cardiac Rehabilitation Programs; QOL: Quality of Life; ACS: Acute Coronary Syndrome; WHOQOL-BREF: World Health Organization Quality Of Life - Short Form.

\section{Acknowledgements}

The authors want to thank the medical department (Cardiology) at University Kebangsaan Malaysia Medical Center (UKMMC) for the support.

\section{Ethics approval and consent to participate}

The Ethics Committee of University Putra Malaysia and University Kebangsaan Malaysia Medical Center approved the study (FPSK(EXP15)P075 / FF-2015-249). All participants of study gave written informed consent.

\section{References}

1. Mensah GA, Roth GA, Fuster V. The Global Burden of Cardiovascular Diseases and Risk Factors: 2020 and Beyond. Journal of the American College of Cardiology. 2019;74 (20):2529-2532. Doi:10.1016/j.jacc.2019.10.009.

2. Gheorghe A, Griffiths U, Murphy A. et al. The economic burden of cardiovascular disease and hypertension in low- and middle-income countries: a systematic review. BMC Public Health. 2018;18:975. https://doi.org/10.1186/s12889-0185806-x.

3. Sheppard LP, Channer KS. Acute coronary syndromes, Continuing Education in Anesthesia, Critical Care \& Pain. 2004;4(6):175-180.

4. Oldridge N, Pakosh M, Grace SL. A systematic review of recent cardiac rehabilitation metaanalyses in patients with coronary heart disease or heart failure. Future Cardiol. 2019 May;15(3):227249. doi: 10.2217/fca-2018-0085.

5. Anderson L, Taylor RS. Cardiac rehabilitation for people with heart disease: an overview of Cochrane systematic reviews. Cochrane Database of Systematic Reviews. 2014;12: Art. No.: CD011273.

DOI: 10.1002/14651858.CD011273.pub2.

6. Sumner J, Harrison A, Doherty P. The effectiveness of modern cardiac rehabilitation: A systematic review of recent observational studies in non-attenders versus attenders. PLoS ONE. 2017;12(5): e0177658.

7. Yanagawa, Bobbya, Tam, Derrick Y, Mazine, Aminea, Tricco, Andrea C. Systematic review and 
meta-analysis in cardiac surgery, Current Opinion in Cardiology. March 2018;33(2):184-189.

8. Mehra MR, Desai SS, Kuy SR, Henry TD, Patel AN. Cardiovascular Disease, Drug Therapy, and Mortality in Covid-19. The New England Journal Of Medicine.2020; 382:e102. DOI: 10.1056/NEJMoa2007621.

9. Gallagher D, O'Regan C, Savva GM, Cronin H, Lawlor BA, Kenny RA. Depression, anxiety and cardiovascular disease: Which symptoms are associated with increased risk in community dwelling older adults? Journal of Affective Disorder. 2012;142:132-138.

10. Valencia HE, Savage PD, Ades PA. Cardiac rehabilitation participation in underserved populations: minorities, low socioeconomic and rural residents. Journal of Cardiopulmonary Rehabilitation. 2011;31:203-210.

11. Graham I, Atar D, Borch-Johnsen K, Boysen G, Burell G, Cifkova R, et al. European guidelines on cardiovascular disease prevention in clinical practice: Fourth Joint Task Force of the European Society of Cardiology and other societies on cardiovascular disease prevention in clinical practice. European Journal of Cardiovascular Prevention Rehabilitation. 2007;14(2):S1-113.

12. Maddox TM, Reid KJ, Spertus JA, Mittleman M, Krumholz HM, Parashar S, et al. Angina at one year after myocardial infarction: Prevalence and associated findings. Archives of Internal Medicine. 2008;168(12):1310-1316.

13. Shepherd CW, While AE. Cardiac rehabilitation and quality of life: A systematic review. 2012;49(6):0-0.

doi:10.1016/j.ijnurstu.2011.11.019.

14. Candelaria D, Randall S, Ladak, L, et al. Healthrelated quality of life and exercise-based cardiac rehabilitation in contemporary acute coronary syndrome patients: a systematic review and metaanalysis. Qual Life Res. 2020;29:579-592.

15. Kemi J, Wisloff U. High-intensity aerobic exercise training improves the heart in health and disease. Journal of Cardiopulmonary Rehabilitation and Prevention. 2009;30:2-11.

16. Zullo M, Dolansky M, Jackson L. Cardiac rehabilitation, health behaviors and body mass index post-myocardial. Journal of Cardiopulmonary Rehabilitation and Prevention. 2010;30:28-34.

17. Taylor RS, Sagar VA, Davies EJ, et al. Exercisebased rehabilitation for heart failure. Cochrane Database Syst. Rev 2014;7. Doi:10.1002/14651858.CD003331.pub4.
18. Anchah L, Hassali MA, Lim MSH, Mohamed Ibrahim MI, Sim KH, Ong TK. Health related quality of life assessment in acute coronary syndrome patients: the effectiveness of early phase 1 cardiac rehabilitation. Health and Quality Outcomes. 2017;15:10.

19. Bethell HJ, Lewin RJ, Dalal HM. Cardiac rehabilitation: it works so why isn't it done? The British journal of general practice : the journal of the Royal College of General Practitioners. 2008;58(555):677-679.

20. Suaya JA, Shepard DS, Normand SL, Ades PA, Prottas J, Stason WB. Use of cardiac rehabilitation by Medicare beneficiaries after myocardial infarction or cardiac bypass surgery. Circulation. 2007;116:1653-1662.

21. Keteyian S, Pina I, Hibner B, Fleg J. Clinical role of exercise training in the management of patients with chronic heart failure. Journal of Cardiopulmonary Rehabilitation and Prevention. 2010:30:67-76.

22. Thomas S, Beh L, Nordin RB. Healthcare delivery in Malaysia: changes, challenges and champions. Journal of Public Health in Africa. 2011;2(2):e23.

23. Munro J, Corrigall H, Angus N, Thompson D, Leslie S. Home versus hospital-based cardiac rehabilitation: a systematic review. Rural Remote Health. 2011;11(2):1532.

24. Deeken J, Ingham J, Taylor K, Mangan P, Yabroff K. Care for the caregivers: A review of self-report instruments developed to measure the burden, needs, and quality of life of informal caregivers. Journal of Pain Symptom Management. 2003; 26:922-953.

25. Schulz R, Sherwood P. Supporting family caregivers: Physical and mental health effects of family caregiving; Adverse - and even positive outcomes in a chronic stress experience. American Journal of Nursing. 2008;108:23-27.

26. Alavi M, Irajpour A, Giles $\mathrm{T}$, Rabiei $\mathrm{K}$, Sarrafzadegan N. Barriers to education in cardiac rehabilitation within an Iranian society: A qualitative descriptive study. Contemporary Nurse. 2013;44(2):204-214.

27. Rowlands O, Parker G. Informal carers. Result of an independent study carried out on behalf of the Department of Health as part of the 1995 General Household Survey. London:The Stationary Office; 1998.

28. Wood DA, Kotseva K, Conolly S, Jennings C, Mead A, Jones J, et al. EUROACTION Study Group. Nurse-coordinated multidisciplinary family-based cardiovascular disease prevention program (EUROACTION) for patients with 
coronary heart disease and asymptomatic individuals at high risk of cardiovascular disease: a paired cluster-randomized trial. Lancet. 2008;371: 1999-2012.

29. WHOQOL Group. Development of the WHOQOL: Rationale and current status. International Journal of Mental Health. 1994a;23 (3):24-56.

30. Ministry of Health, Malaysia. Management of Acute St Segment Evelavion Myocardial Infarction (STEMI) (2 ${ }^{\text {nd }}$ ed.). 2007. Malaysia.

31. Sze CL, Siop S, Lim L. Enrollment and attendance to Cardiac Rehabilitation after Percutaneous Coronary Intervention in Sarawak: A Prospective Study. International Journal of Recent Technology and Engineering.2019;8(1C2):900-903.

32. Yew KL, Leong BK.Comprehensive Cardiac Rehabilitation Program: A Malaysian Experience. 2016. DOI: 10.13140/RG. 2.2.15034.80320.

33. Dankner R, Geulayov G, Ziv A, Novikov I, Goldbourt U, Drory Y. The effect of an educational intervention on coronary artery bypass graft surgery patients' participation rate in cardiac rehabilitation programs: a controlled health care trial. BMC Cardiovascular Disorders. 2011;11:60. doi:10.1186/1471-2261-11-60.

34. WHOQOL Group. The World Health Organization Quality of Life assessment (WHOQOL): Development and general psychometric properties. Social Science Medicine. 1998;46:1569-1585.

35. Skevington SM, Lofty M, O'Connell KA. The World Health Organization's WHOQOL-BREF quality of life assessment: psychometric properties and results of the international field trial. A report from the WHOQOL group. Quality of Life Research. 2004;13:299-310.

36. Najafi M, Sheikhvatan M, Montazeri A, Sheikhfatollahi M. Factor Structure of the World Health Organization's Quality of Life Questionnaire-BREF in Patients with Coronary Artery Disease. International journal of preventive medicine. 2013;4(9):1052-1058.

37. Department of Statistics Malaysia. Current population estimates, Malaysia, 2018-2019. 2019. https://dosm.gov.my/v1/index.php?r=colum n/pdfPrev\&id=aWJZRkJ4UEdKcUZpT2tVT090S npydz09.

38. Lu HT, Nordin R. Ethnic differences in the occurrence if acute coronary syndrome: results of the Malaysian National Cardiovascular Disease (NCVD) Database Registry (March 2006 February 2010). BMC Cardiovascular Disorders. 2013;13:97.
39. Mosca L, Barrett-Connor E, Kass-Wenger $\mathrm{N}$. Sex/Gender differences in cardiovascular disease prevention: what a difference a decade makes.Circulation.2011;124 (19):2145-2154.

40. Yahya R, Muhamad R, Yusoff HM. Association between Knowledge, Attitude and Practice on Cardiovascular Disease among Women in Kelantan, Malaysia. International Journal of Collaborative Research on Internal Medicine \& Public Health. 2012;4(8):1507-1523.

41. Zuhaid M, Kazmi S, Farooq U, Khan IA, Aziz T, Aziz S, Rahim M. Knowledge of modifiable risk factors of cardiovascular diseases among patients with acute myocardial infarction. Journal of Ayub Medical College Abbottabad. 2014;26(3):364-367.

42. Hwang SY, Kim JS. Risk factor-tailored small group education for patients with first-time acute coronary syndrome. Asian Nursing Research. 2015;9:291-297.

43. Drewnowski A, Evans WJ. Nutrition, physical activity, and quality of life in older adults: Summary. Journal of Gerontology. 2001;56A(Special Issue II): 89-94.

44. Dolansky M, Zullo M, Boxer R, Moore S. Initial efficacy of a cardiac rehabilitation transition program: Cardiac TRUST. Journal of Gerontological Nursing. 2011;37(12):36.

45. Mattson M, Gibb HJ. Linking health communication with social support. In: Mattson M, Gibb Hall J. Health as Communication Nexus: A Service-learning Approach. Dubuque, IA: Kendall Hunt. 2011;181-218.

46. Boutin-Foster C. Getting to the heart of social support: a qualitative analysis of types of instrumental support that are most helpful in motivating cardiac risk factor modification. HeartLung. 2005;34(1):22-29.

47. Sadeghi M, Garakyaraghi M, Taghavi M, Khosravi M, Sarrafzadegan N, Roohafza H. The impacts of cardiac rehabilitation program on exercise capacity, quality of life, functional status of coronary artery disease patients with left ventricular dysfunction. Rehabilitation Nursing. 2015;40(5):305-309.

48. Herman R, Liebergall M, Rott D. Correlation between participation in a cardiac rehabilitation program and quality of life of patients with coronary artery disease. Rehabilitation Nursing. 2014;39(4):192-197.

49. Brown JPR, Clark AM, Dalal H, Welch K, Taylor RS. Effect of patient education in the management of coronary heart disease: a systematic review and meta- analysis of randomized controlled trials. 
Cochrane Database of Systematic Reviews. 2011; 12:CD008895.

50. Bosworth HB, Siegler IC, Olsen MK, Brummett $\mathrm{BH}$, Barefoot JC, Williams RB, Clapp-Channing NE, Mark DB. Social support and quality of life in patients with coronary artery disease. Quality of Life Research. 2000;9(7):829-839.

51. Savage PD, Sanderson BK, Brown TM, Berry K, Ades PA. Clinical research in cardiac rehabilitation and secondary prevention: Looking back and moving forward. Journal of Cardiopulmonary Rehabilitation and Prevention. 2011;31(6):333-341.

52. Ghisi GL, Abdallah F, Grace SL, Thomas S, Oh P. A systematic review of patient education in cardiac patients: do they increase knowledge and promote health behavior change? Patient Education and Counseling. 2014;95(2):160-174.

53. Grace SL, Grewal K, Arthur HM, Abramson BL, Stewart DE. A prospective, controlled multi-site study of psychosocial and behavioral change following women's cardiac rehabilitation participation. Journal of Women's Health. 2008;(17)2:241-248.

54. Grace SL, Angevaare KL, Reid RD, Oh P, Anand S, Gupta M, Stewart DE. Effectiveness of inpatient and outpatient strategies in increasing referral and utilization of cardiac rehabilitation: A prospective multi-site study. Implementation Science. 2012;7(120):n.p. doi: 10.1186/17485908-7-120.

55. Khan MS, Jafary FH, Jafar TH, Faruqui AM, Rasool SI, Hatcher J, Chaturvedi N. Knowledge of modifiable risk factors of heart disease among patients with acute myocardial infarction in Karachi, Pakistan: a cross sectional study. BMC Cardiovascular Disorders. 2006;6:18.

56. Brownson RC, Boehmer TK, Luke DA. Declining rates of physical activity in the United States: what are the contributors? Annual Review of Public Health. 2005;26:421-443.

57. Reges O, Vilchinsky N, Leibowitz M, Khaskia A, Mosseri, M, D'Kark J. Change in health behaviors following acute coronary syndrome: Arab-Jewish differences. European Journal of Preventive Cardiology. 2015;22(4):458-467.

58. Louredo AB.de, Leite AL, Coelho S, Gisela RF, Fernandes M, Blascovi-Assis S. Instruments to assess quality of life in patients with heart failure. Fisioterapia em Movimento. 2015;28(4):851-858.

\section{Source of Support: Nil}

Conflict of Interest: Nil

Rajen Durai et al ASIAN PACIFIC JOURNAL OF NURSING AND HEALTH SCIENCES, 2021; 4(1):12-21 